\title{
Effects of $\beta$-Blocker (Propranolol) on the Blood Pressure, Heart Weight and Heart Rate of Spontaneously Hypertensive Rat Fed with High-Salt, High- Carbohydrate, and Low-Protein Diet
}

\author{
Hideo Ueda, * Atsushi Sakamoto, * Haruo Kobayashi, ${ }^{*}$ Katsumi \\ Kaneko, ${ }^{*}$ Yoshio Suganuma, ${ }^{* *}$ and Naohiro SaIto**
}

The aim of this study is to examine the effects of a $\beta$-blocker (propranolol) upon the blood pressure, heart weight and heart rate in Spontaneously Hypertensive Rat (SHR) fed with different kind of diet by the combination of high salt and high carbohydrate. Folkow noticed the effect of propranolol on the blood pressure of SHR, whereas, the other researchers did not observe the hypotensive action of propranolol.

\section{Methods and Materials:}

Fifty, 6 week-old, SHR were divided into 5 groups and each group has been fed with 5 different diet and propranolol for 10 weeks. Then the animals were sacrificed, the weight of main organs was measured and the blood and tissues were examined.

The blood pressure of the animals were measured every week by the tail-water plethysmographic method. The heart rate was examined by ECG recording at the end of 10 weeks feeding. Ten Wistar rats were used as controls.

Ten $\mathrm{mg} / \mathrm{Kg}$ body weight of propranolol was given daily by mouth to 2 groups of SHR fed with common diet and high-salt, high-carbohydrate diet as can be seen in the following. To assure the resorption of propranolol, in 5 rats of each SHR fed with propranolol, $10 \mathrm{mg} / \mathrm{Kg}$ of propranolol was given intraperitoneally every day.

\begin{tabular}{l|l|l}
\hline Control & female Wistar rats & Common diet \\
SHR 1 & female & Common diet \\
SHR 2 & fermale & Common diet with propranolol \\
SHR 3 & female & High-salt diet (1\%NaCl water) \\
SHR 4 & female & High-salt, high-carbohydrate, low-protein (Akita diet) \\
SHR 5 & female & Akita diet with propranolol
\end{tabular}

From the Clinical Research Institute,* Central Hospital, JNR, 2-1-3, Yoyogi, Shibuya-ku, Tokyo; and Kowa Tokyo Institute,** 2-17-43, Noguchi-cho, Higashimurayama City, Tokyo. 
Results :

\begin{tabular}{c|c|c|c}
\hline Group & $\begin{array}{c}\text { Blood Pressure } \\
(\text { mean } \pm \text { SD) }\end{array}$ & $\begin{array}{c}\text { Heart Weight/ } \\
\text { Body Weight }\end{array}$ & $\begin{array}{c}\text { Heart Rate } \\
\text { (mean } \pm \text { SD) }\end{array}$ \\
\hline Control & $132.5 \pm 10.7$ & 0.33 & \\
SHR 1 & $183.5 \pm 10.7$ & 0.43 & $369 \pm 48$ \\
SHR 2 & $180.0 \pm 8.2$ & 0.43 & $332 \pm 30$ \\
SHR 3 & $199.0 \pm 13.9$ & 0.51 & $422 \pm 45$ \\
SHR 4 & $205.5 \pm 7.9$ & 0.55 & $320 \pm 34$ \\
SHR 5 & $188.5 \pm 9.2$ & 0.50 &
\end{tabular}

The blood pressure of SHR 5 is lower than that of SHR $4(p<0.01)$, and the heart weight and the heart rate of SHR 5 are smaller than the SHR 4 $(\mathrm{p}<0.01)$.

These results show that propranolol reduces the high blood pressure, hypertrophy of the heart and the heart rate in SHR fed with Akita diet.

There are no significant differences of blood pressure, heart weight and heart rate between SHR 1 and SHR 2. These data may mean that propranolol has no effect on the blood pressure in SHR fed with common diet.

The doses of propranolol, $10 \mathrm{mg}$ and $20 \mathrm{mg} / \mathrm{Kg}$ body weight, showed similar effect on blood pressure in SHR 5 .

The SHR fed with Akita diet showed most marked high blood pressure (Clinical Science 45 : 49, 1973, Singapore Med J 14: 147, 1973).

\section{Summary and Conclusion:}

1. The $\beta$-adrenergic receptor blocker (propranolol) does not affect the blood pressure and heart weight of SHR fed with common diet.

2. Propranolol lowers the level of blood pressure, decreases the heart weight and heart rate in SHR fed with high-salt, high-carbohydrate, and low-protein diet. The lowered level of blood pressure in SHR fed with above mentioned diet and propranolol is similar to the level of SHR fed with common diet.

3. The blood pressure of SHR with high salt diet is higher than the SHR with common diet and is lower than the SHR fed with high-salt, highcarbohydrate, and low-protein diet. 